\title{
Structural, Vibrational, Morphological, Antibacterial and Electrical Conductivity Examination of Polystyrene Graphite Composite Films
}

\author{
Soumya Chatterjee, Devargya Chakraborty, T.Theivasanthi, N.Hariram, M.S.Revathy, \\ P.G.Gurusamy Pandian
}

\begin{abstract}
High conductive filler graphite is added with polystyrene to prepare conductive polymer composites. Solution casting technique was implemented to prepare polystyrene films. Benzene is used as a solvent to dissolve polystyrene. Graphite is loaded in these polystyrene films with various concentrations from $0.5 \%$ to $2.5 \%$ as a filler. The reinforcement of graphite particles in polystyrene matrix is studied through various characterization techniques like XRD, FTIR and SEM analyses. Antibacterial studies are performed for two microorganisms. Electrical conductivity of the films are measured using LCR meter.
\end{abstract}

Keywords : Graphite, Polystyrene, XRD, FTIR, SEM, Antibacterial assay.

\section{INTRODUCTION}

Conductive fillers in polymers occupied the flexible electronics market for display applications. In the last few decades, polymer thin films has grabbed the attention of many great researchers because of its diverse use in various fields such as it can be used as an adhesives, as a lubricant and also as membranes and for that purpose the major properties of the polymeric films were studied and it was found that they are dependent on the interfacial characteristics [1]. Since then many experiments have been carried out on the polymeric films to investigate the interfacial characteristics. From this experiments many important observations have been made like the glass transition temperature $\left(\mathrm{T}_{\mathrm{g}}\right)$ of the films which is found to be lower than their bulk state [2][3]. The structural characteristics of the polymeric films can be studied using various techniques like the $\mathrm{X}$ ray scattering [4], secondary ion mass spectroscopy [5],

Revised Manuscript Received on December 05, 2019.

* Correspondence Author

Soumya Chatterjee, Department of Chemical Engineering Haldia Institute of Technology, Haldia, West Bengal, India Email: soumya.hithaldia@yahoo.com

Devargya Chakraborty, Department of Chemical Engineering Haldia Institute of Technology, Haldia, West Bengal, India

T.Theivasanthi, Physics, Kalasalingam Academy of Research and Education, Krishnankoil, Virudhunagar, India.

Email: theivasanthi@gmail.com

M.S.Revathy, Physics, Kalasalingam Academy of Research and Education, Krishnankoil,Virudhunagar, India.

Email: revz.vijay@gmail.com

N.Hariram, Physics, Department of Biotechnology, Kalasalingam Academy of research and Education, Krishnankoil, Virudhunagar,India, Email: n.hariram@klu.ac.in.

P.G.Gurusamy Pandian*, Department of Automobile Engineering, Kalasalingam Academy of research and Education, Krishnankoil, Virudhunagar India. Email : pro@klu.ac.in

scanning probe microscopy [6] and many other techniques. Since there are so many polymers which are used in recent days to form the polymeric films, polystyrene is one of the important polymers which has application in various fields like the electronic packaging and many others [7][8]. Polystyrene is an example of thermoplastic polymer, produced from monomer unit styrene. Polystyrene is rigid solid in its solid form, but heating changes to its liquid form and used again for molding and extrusion [9].

Polystyrene is a kind of plastic which holds some remarkable properties like excellent dielectric property, dimensionally stable and the resistance towards chemicals are also very good. Starting from electronic industries to kitchen appliances everywhere this plastic is used [10]. Adding thermal conductive fillers enhance the properties of the films to a greater extent. And for that various kinds of fillers has been used in past like the carbon black, carbon fiber etc.[11][12][13][14][15][16] , graphite could be one of the ideal fillers as many researchers in past have used graphite as a filler to enhance the properties [17].

Graphite was used as conducting filler for preparing polymer composites since it is having more electrical conductivity [18][19]. In Graphite the carbon atoms are bonded covalently and the geometry of the arrangement of the atoms are hexagonal. And the layers of the Graphite are bonded by very weak Van der Walls forces [10]. So the graphite particles are then dispersed with the polymer matrix homogenously and for that sonicator is used and then the composites are prepared by the in-situ polymerization technique. The reason for using this technique is that there no appreciable changes takes place in the electrical or mechanical properties as it has been reported that blending and extruding often results in reducing the properties of the composites which is not at all desirable [20].

Polymer composites are prepared with conductive fillers. They are superior to metallic conductors because of low cost, light weight and corrosion resistance [21]. The efficiency of the nanocomposite is decided by the filler chemical structure, its surface area, morphology and the interaction between the polymer and filler. When a filler is added to a polymer with a very good solvent, strong interactions occur between the polymer and the filler. The volume of the filler can increase the viscosity of the composite [22].This work was initiated to explore polystyrene graphite nanocomposite as a multifunctional material for various Development of electrical 


\section{Structural, Vibrational, Morphological, Antibacterial and Electrical Conductivity Studies of Polystyrene Graphite Composite Films}

conductivity in polymers can be achieved with nanocomposites.

Graphite consists of many stacked layers of nano sheets. The electrical conductivity of graphite is $10^{4} \mathrm{~S} / \mathrm{cm}$ [23]. The origin of high electrical conductivity and superconductivity in polystyrene films is reported by Nikolaeva et al. The formation of covalent bonds between PS and graphite create some mechanical stresses which gives rise to superconducting property. A conductivity level of more than $20 \mathrm{~S} \cdot \mathrm{m}-1$ can be achieved through the formation of composites for the polymers. This superior electrical conductivity may be attributed only to the structure of nanocomposites [24]. Polystyrene loaded with graphite particles can be used for insulated sheathing in construction applications. The buildings can be laminated with polymeric film facers as water resistant barriers which can eliminate the need for house wrap.

Increased loading of graphite in polystyrene films offers more electrical conductivity, high young's modulus and a protective electromagnetic shielding. But loading of graphite more than $40 \%$ graphite filler leads to more agglomeration which leads to deterioration of the film [25]. In this work, polystyrene graphite composite is prepared with very small loading of filler.

\section{MATERIALS AND METHODS}

\section{A.Materials}

Commercial grade poly-styrene $\left[\left(\mathrm{C}_{8} \mathrm{H}_{8}\right)_{\mathrm{n}}\right.$ and density at $20^{\circ} \mathrm{C}$ is $\left.1.04-1.065 \mathrm{~g} / \mathrm{ml}\right]$ and the commercial grade $99 \%$ pure Graphite was obtained from Reachem laboratory chemicals private limited. Commercial grade benzene [Average molecular weight $=78.11$ and distillation range is $79-81^{\circ} \mathrm{C}$ and density at $20^{\circ} \mathrm{C} 0.877-0.880 \mathrm{~g} / \mathrm{ml}$ ] was supplied by Rankem laboratory.

\section{B.Formation of Polystyrene/ Graphite Films}

The polystyrene film is formed by the solution casting technique followed by solvent evaporation process. In solvent evaporation method, the film formation occurs at room temperature. When the solvent evaporates, voids are produced. The film formation and the thickness of the film depends mainly on the concentration of the polystyrene pellets corresponding to the volume of the solvent. The colloid concentration increases and the colloid shrinkage occur. Void closure occurs which leads to the formation of the film [26].10gm of poly-styrene pellets was taken and added with $45 \mathrm{ml}$ of benzene. Then the solution is put in the magnetic stirrer for almost $2 \mathrm{hrs}$ so that the pellets get dissolved in the solvent completely. The solution was poured on a glass slab (which was cleaned with distilled water and acetone) and spread it evenly and the solvent evaporated for almost $36 \mathrm{hrs}$ and then the polystyrene film was obtained. Graphite is loaded with polystyrene films in various concentrations from $0.5 \%, 1 \%, 1.5 \%, 2 \%$ and $2.5 \%$.After the matrix was formed, the solution was kept in the sonicator for $20 \mathrm{~min}$ so that the homogeneity of the matrix should be maintained. The solution was poured on the slab till the solvent gets evaporated and then the films were made.

\section{RESULTS AND DISUSSION}

\section{A.XRD Studies}

XRD is an important tool for studying the intercalation of fillers in polymer matrices. XRD reveals a successful preparation of polystyrene graphite composite. The chemical interaction between polystyrene and graphite is confirmed. The proper mixing of PS and the galleries of Graphite can be seen through the XRD of nano-composite which is shown in Fig. 1. The samples were scanned from the range of $2 \theta=0$ to $2 \theta=30$ (degrees). A peak at $2 \theta=26.35$ (degrees) corresponding to 002 plane of Graphite was observed. A broad peak showing the amorphous nature of PS is present at $2 \theta=15-25$ (degrees) [27]. There is no change in d-spacing and $2 \theta$ of 002 peak of Graphite in the nano-composites. The intensity of the XRD peaks increases with the loading of graphite. As the loading of graphite increases, the crystallinity of the polymer increases which is confirmed from XRD analysis. The $\mathrm{d}$ spacing value for graphite peak is found to be $3.4 \AA$ corresponding to $2 \theta=26^{\circ}$. The fraction of the crystalline phase increases with the increase in filler content which shows a high affinity between polystyrene and graphite. 


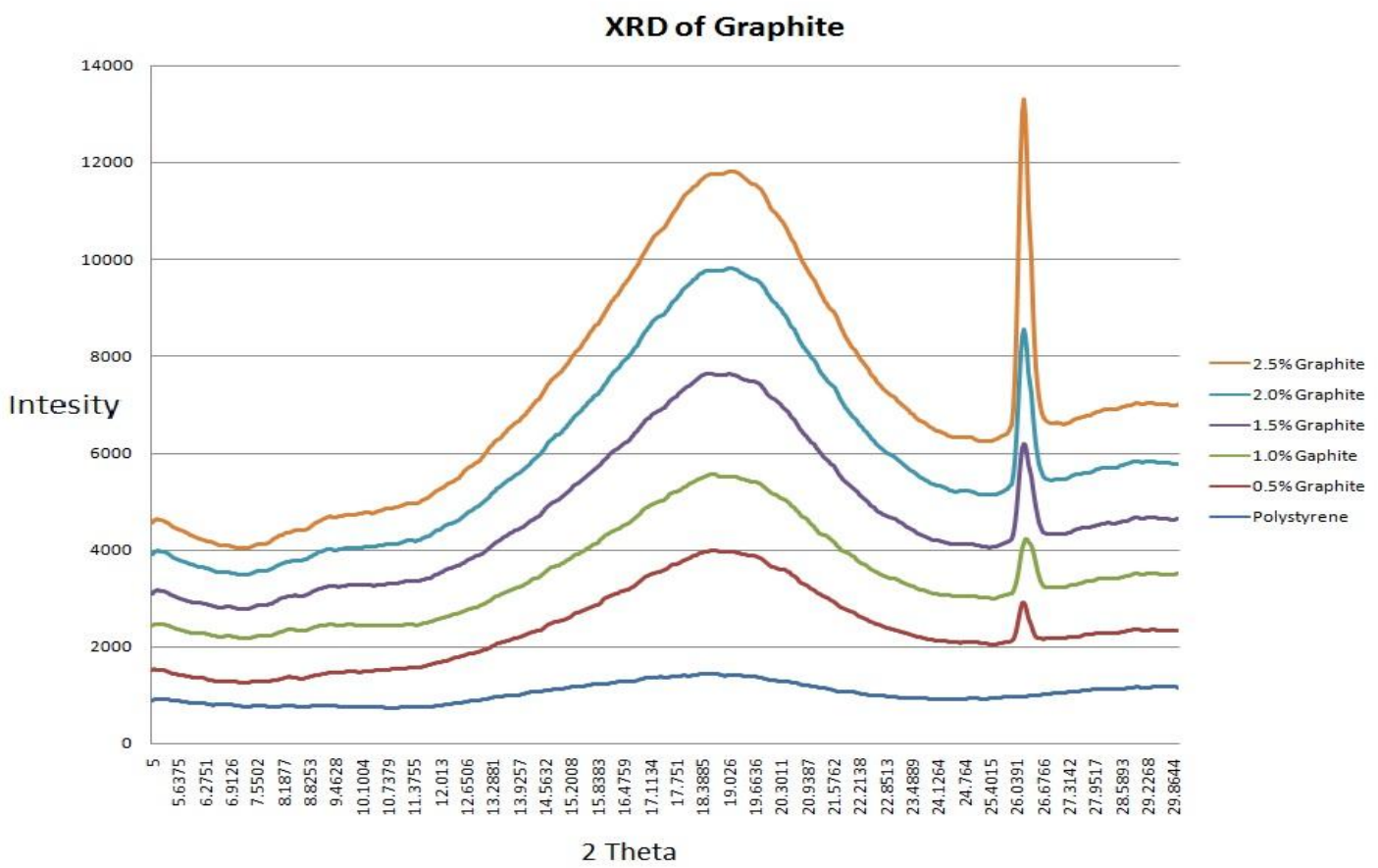

Fig. 1. XRD-graphs of the Graphite polystyrene samples

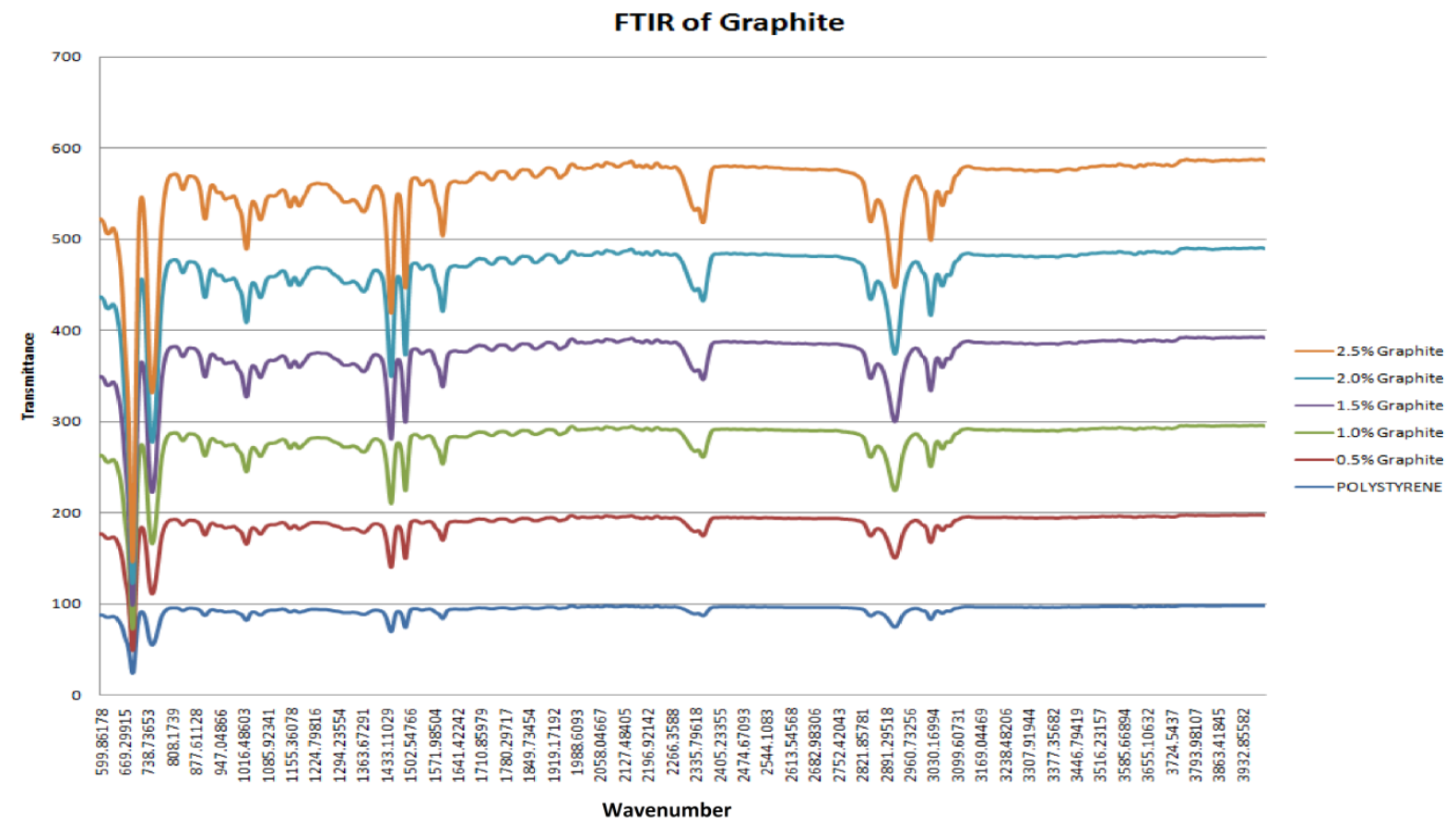

Fig. 2. FTIR graphs of the samples of graphite with polystyrene

\section{B.Fourier transmission infrared spectroscopy (FTIR)studies}

Fig. 2. Shows the FTIR spectra of PS, and nano-composites. As seen in figure PS composites give the information of $\mathrm{OH}$ group, aromatic $\mathrm{C}=\mathrm{C}$ vibration and phenyl ring. It is noticed at concern vibrational assignment bands at 3442, $1377 \mathrm{~cm}^{-1}, 1448,1492$ and $1595 \mathrm{~cm}^{-1}$ correspond to stretching $\mathrm{OH}$ vibration and aromatic $\mathrm{C}=\mathrm{C}$ vibration. In addition, the peaks at 756 and 699 $\mathrm{cm}^{-1}$ correspond to out-of plane Vibration modes of phenyl ring of PS [28] [29]. Furthermore, the spectrum of nano-composite, the absorption of graphite and PS was found without change or shift in their characteristic bands. This indicates that there is no chemical interaction between the graphite and the PS molecules during processing. The intensity of all the vibrations increases as the loading of graphite filler increases. No shift in the peaks was found upon loading. The studies of chemical composition at the interface from FTIR analysis is an important area to analyse the properties of polymer composites [30]. The FTIR of graphite is not having any functional groups because of pauli's blocking. When the final

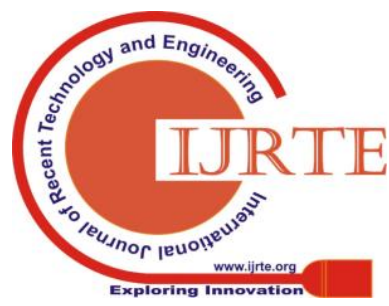




\section{Structural, Vibrational, Morphological, Antibacterial and Electrical Conductivity Studies of Polystyrene Graphite Composite Films}

transition states are completely filled and no electron can do transition, Pauli's blocking occurs i.e conduction band is completely filled with electrons. The spectra is like a flat line. The absorption is independent of the frequency and material properties [31]. The FTIR spectrum of pure graphite should be flat since there are only polyaromatic layers. When the composites are made with a polymer and graphite, a peak at $2 \theta=26^{\circ}$ appears for graphite in XRD analysis. But no peak is there for graphite in the FTIR spectrum of the composites. But the intensity of the polymer peak increases in both the cases when the filler loading increases.

\section{C.Scanning electron microscopy(SEM) studies}

The SEM pictures show a homogenous dispersion of graphite in polystyrene and the films are smooth. There is no agglomeration of graphite particles in the polymer film. It can be seen from Fig.3. shows that Graphite is having a loose and porous vermicular structure which is similar to that of reported by Song et al.[32]. The porous structure confirms a high surface area of graphite particles.

\section{D.Antibacterial studies}

The antimicrobial studies are performed for two organisms Staphylococcus aureas MTCC 96 and E.coli
MTCC 1652. The bacterial sample of $10^{-6}$ cells are loaded in $100 \mu 1$ liquid samples. Bacterial culture is prepared by inoculating micro-organisms in a $100 \mathrm{ml}$ of sterile medium and incubating for $24 \mathrm{~h}$ at $37^{\circ} \mathrm{C}$. The dilutions of the bacterial sample were spread over the agar plates and kept at $37^{\circ} \mathrm{C}$ for 24hrs. The sterilized medium was cooled to $40{ }^{\circ} \mathrm{C}$ and poured into the petri dishes and the media was allowed to solidify at room temperature. Antimicrobial activity of the crude extracts was determined by the agar well diffusion method. All the test organisms were inoculated in LB broth ( $\mathrm{pH}$ 7.0.) for 8 hours. The optical density of the suspensions was adjusted to 0.5 with the help of a spectrophotometer. Isolates were grown on LB agar plates by using sterile plastic inoculation loop and L rod. A $100 \mu \mathrm{l}$ of $10^{-6}$ cells were spread over the LB agar plate. Plates were incubated at $37^{\circ} \mathrm{C}$ for 48 hours. Triplicate plates were maintained for each organism. The antibacterial activity of the PS graphite composite films was assessed by measuring the minimum inhibitory concentration and minimum bactericidal concentration (Fig.4).

A clear zone was observed around the disc which confirms the presence of inhibition of bacterial growth. The size of the zone of inhibition was measured in millimeters $[34,35]$.
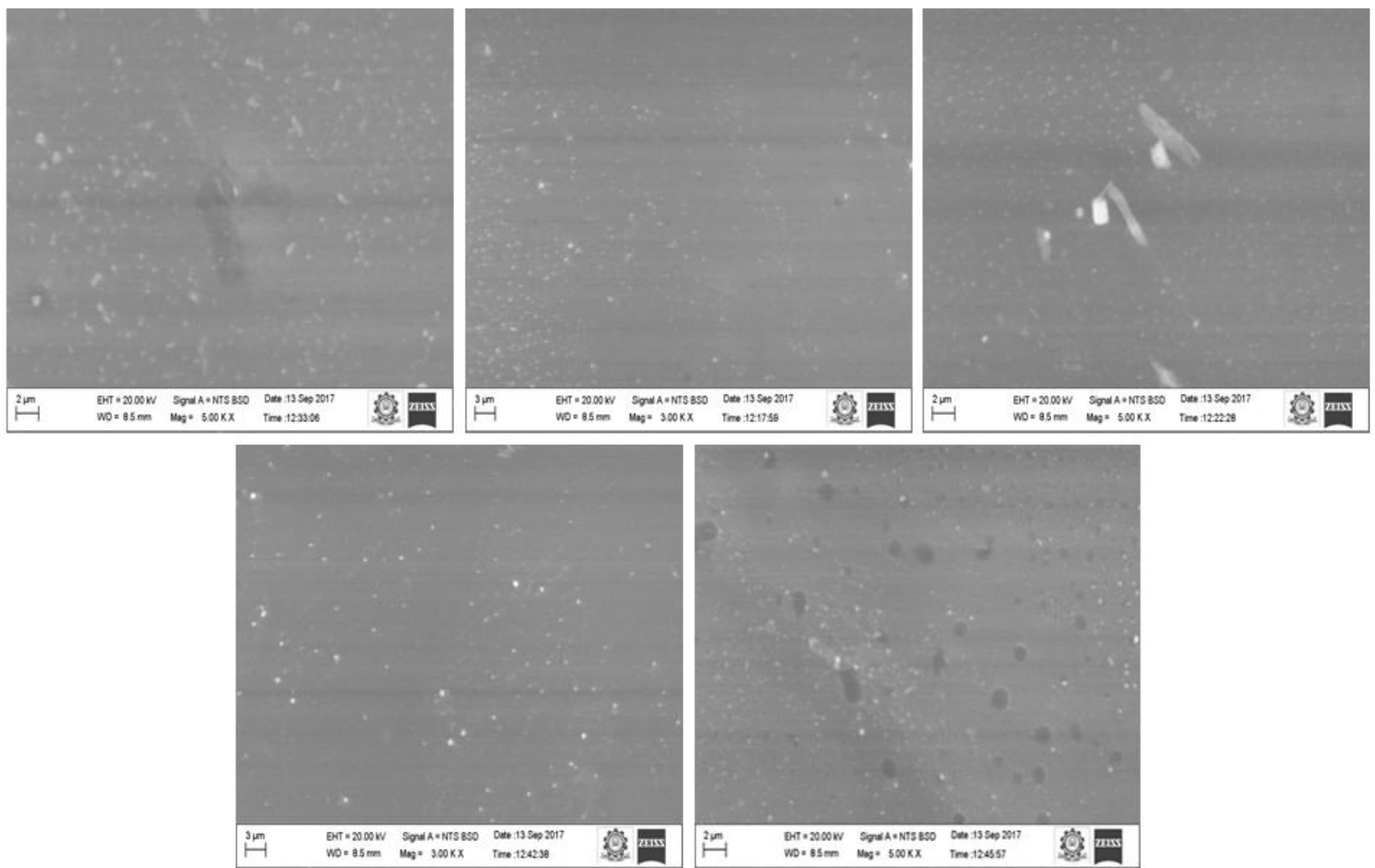

Fig. 3.SEM images for graphite incorporated PS samples for graphite loading of $0.5 \%, 1 \%, 1.5 \%, 2 \%, 2.5 \%$. 


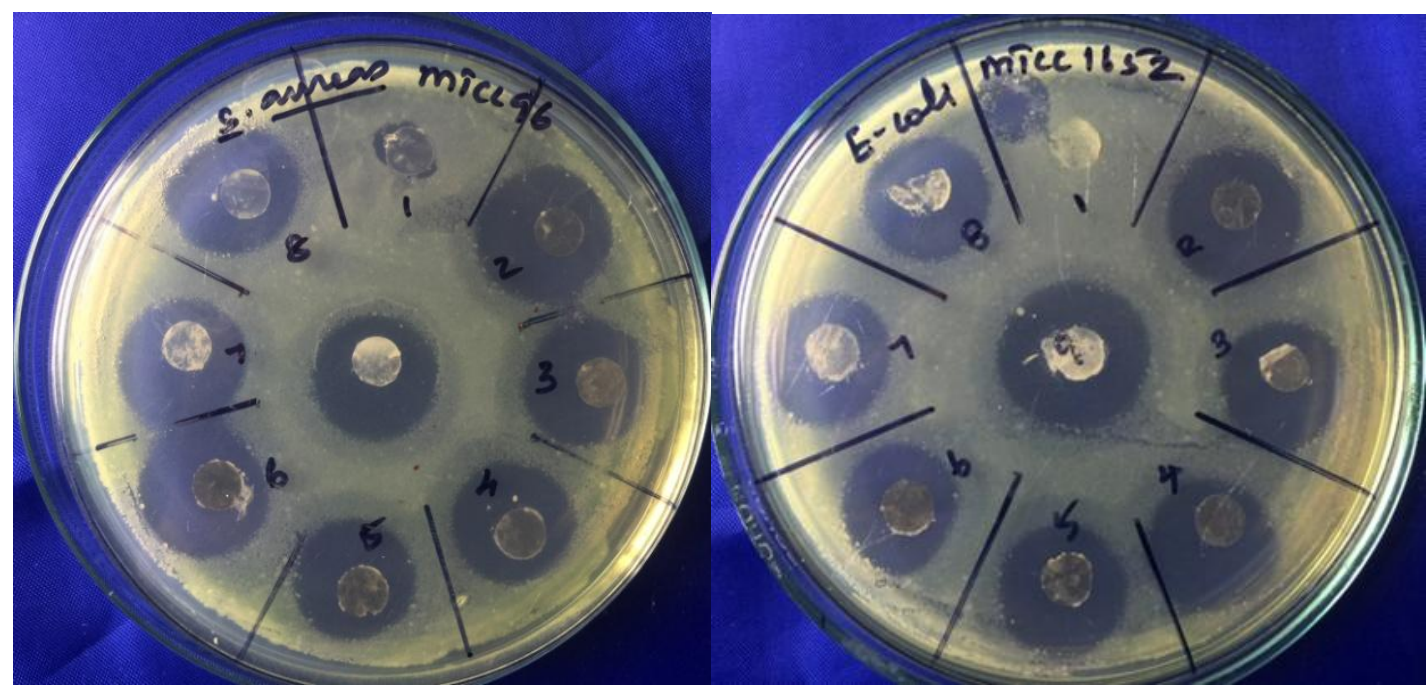

Fig. 4. Zone of inhibition of graphite incorporated PS samples for graphite loading of $0.5 \%, 1 \%, 1.5 \%, 2 \%, 2.5 \%$

\section{E. Electrical ConductivityMeasurements}

The physics behind carbon based structures is very important for studying the percolation conduction process in nanocomposites. The electronic property of graphite arises from its stacked structure. The conductive particles in polymers enable the conduction above the percolation threshold. Composites with conductive fillers can be explained with percolation theory. In composites, the conductive particles are having a very high conductance. If the loading is small, the composite will have a very high resistance. At some fraction of the filler, the insulator becomes a conductor. The filling fraction value at which the insulator becomes a conductor is known as percolation threshold. The composite will become a metal like material [31]. A high aspect ratio of graphite sheets is the reason for improvement in electrical conductivity of the composite. High loading of graphite gives rise to poor mechanical properties and high density of the composite. There is an optimum level of loading of the filler in the matrix to make the composite with remarkable properties. The addition of graphite in polystyrene may increase the glass transition temperature of the composite which depends on the mobility of the chain segments and this is true only for low loading of the filler [27].

For designing a good performance of composites, the following factors should be considered (i) selection of filler and matrix (ii) thermodynamic and rheological properties of filler and matrix (iii) Processing conditions. During the synthesis of nanocomposites, the chemical structure of polymer is controlled and thereby the attraction between the polymer and filler is increased. This leads to better disaggregation and homogenous dispersion of the filler in the matrix. Thus percolation threshold can be achieved even for small loading of the filler. [32]. The polymer composites can be made as functional through the percolation of high surface area conductive particles. The effective surface area may decrease due to aggregation after composite formation [33]. The electrical conductivity study of the films is performed in LCR meter. Fig.5 shows the Electrical conductivity measurements of graphite incorporated PS samples for graphite loading of $0.5 \%, 1 \%, 1.5 \%, 2 \%, 2.5 \%$. Polystyrene with $1 \%$ graphite shows more conductivity than other samples which is evident from the graph.

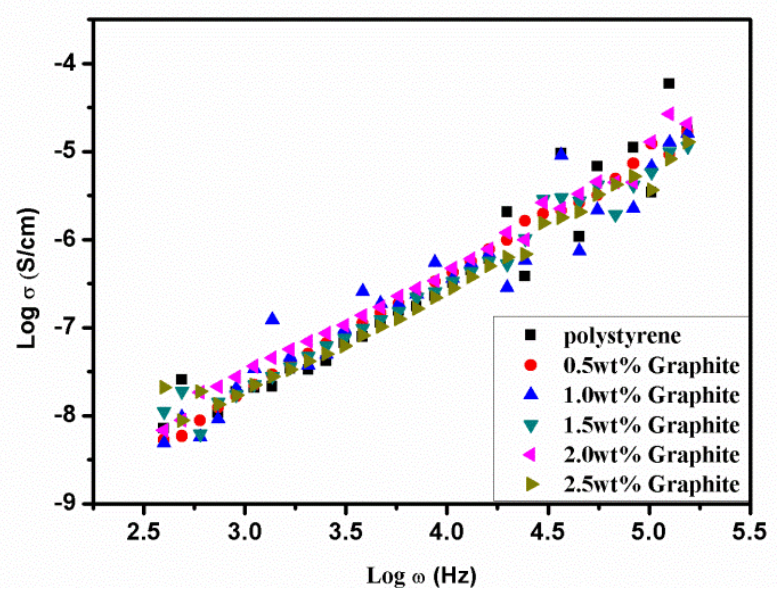

Fig. 5. Electrical conductivity evaluationof graphite incorporated PS samples for graphite loading of $0.5 \%$, $1 \%, 1.5 \%, 2 \%, 2.5 \%$.

\section{CONCLUSION}

The cost effective polystyrene/ graphite nano-composites was prepared by a solution casting method. XRD shows that the crystallinity increases upon increasing the graphite content. FTIR shows that there is no chemical interaction between Graphite and PS molecules. SEM pictures give the information about uniform distribution and three-dimensional network of Graphite in PS matrix. Antibacterial studies and Electrical conductivity measurements show good results.

\section{REFERENCES}

1. I.C. Sanchez (Ed.), Physics of Polymer Surfaces and Interfaces, Butterworth-Heinemann, Boston, 1992.

2. J.L. Keddie, R.A.L. Jones, R.A. Cory, "Size-dependent depression of the glass transition temperature in polymer films," Europhys. Lett. vol 27, 1994, pp. 59-64.

3. J.A. Forrest, K. Dalnoki-Veress, J.R. Stevens, J.R. Dutcher, Effect of free surfaces on the glass transition temperature of thin polymer films, Phys. Rev. Lett. 77, 1996, pp. 2002-2005.

4. M. Birkholz, Thin Film Aalysis by X-ray Scattering, Wiley-VCH, Weinheim, 2006.

5. Briggs, Surface Analysis of Polymers by XPS and Static 


\section{Structural, Vibrational, Morphological, Antibacterial and Electrical Conductivity Studies of Polystyrene Graphite Composite Films}

SIMS, Cambridge University Press, Cambridge, 1998

6. B.D. Ratner, V.V. Tsukruk, Scanning Probe Microscopy of Polymers, ACS Symposium Series 694, American Chemical Society, Washington DC, 1998.

7. W. Y. Zhou, S. H. Qi, H. D. Li, Thermochim. Acta. vol. 452, 2007, pp. 36-42. DOI: 10.1016/j.tca.2006.10.01.

8. M. J. Biercuk, M. C. Llaguno, M. Radosavljevic, J. K. Hyun, Appl. Phys. Lett. vol. 80, 2002, 2767-2769. DOI: 10.1063/1.1469696.

9. Zhi Wang, Shichao Li, Zhanjun Wu, "The fabrication and properties of a Graphite nano-sheet/polystyrene composite based on Graphite nano-sheets treated with supercritical water", Composites Science and Technology, vol. 112, 2015, pp. 50-57.

10. Haoming Tu, Lin Ye.Thermal conductive PS/graphite composites. Polym. Adv. Technol. vol. 20, 2009, pp. 21-27.

11. Y. Agari, A. Ueda, S. Nagai, J. Appl. Polym. Sci. vol. 49, 1993, pp. 1625-1634

12. Y. Agari, A. Ueda, M. Tanaka, J. Appl. Polym. Sci.vol. 40, 1990, pp. 929-941.

13. Desharun, B. Jongsomjit, P. Praserthdam, Catal. Commun. vol.9, 2008, pp. 522-528. DOI: 10.1016/j.catcom.2007.08.001.

14. J. Z. Liang, F. H. Li, Polym. Test. vol. 67, 2007, pp. 2665-2674. DOI: 10.1016/ j.compscitech.2007.03.009

15. W. Y. Zhou, S. H. Qi, Q. L. An, H. Z. Zhao, N. L. Liu, Mater. Res Bull. vol. 42, 2007, pp.1863-1873. DOI: 10.1016/ j.materresbull. 2006. 11.047

16. Droval, J. F. Feller, P. Salagnac, P. Glouannec, Polym. Adv. Technol. vol. 17, 2006, pp. 732-745. DOI: 10.1002/pat.777.

17. Peng Xiao, Min Xiao, Kecheng Gong, Polymer, vol. 42, 2001, pp 4813-4816.

18. Saunders DS, Galea SC, Deirmendjian GK. Composite, vol. 24(4), 1993, pp. 309.

19. Ezquerra YA, Kulescza M, alta-Calleja FJ. Synth Met, vol. 915, 1991, pp. 41-43.

20. Dubois PH, Alexander M, Hindryckx F, et al. J Macromol Sci-Rev Macromol Chem Phys, vol. C38, 1998, 511.

21. Abdullah, Nur Munirah, M. Saddam Kamarudin, Anika Zafiah M. Rus, and M. F. L. Abdullah. "Preparation of Conductive Polymer Graphite (PG) Composites." In IOP Conference Series: Materials Science and Engineering," IOP Publishing, vol. 226, no. 1, 2017, pp. 01218.

22. Gheller Jr, Jordão, Manoela V. Ellwanger, and Vinícius Oliveira. "Polymer-filler interactions in a tire compound reinforced with silica," Journal of Elastomers \& Plastics. vol. 48(3), 2016 pp. 217-226.

23. Maiti, Sandip, Nilesh K. Shrivastava, Supratim Suin, and B. B. Khatua. "Polystyrene/MWCNT/graphite nanoplate nanocomposites: efficient electromagnetic interference shielding material through graphite nanoplate-MWCNT-graphite nanoplate networking," ACS applied materials \& interfaces, vol.5, no. 11, 2013, pp. 4712-4724.

24. Nikolaeva, M. N., T. D. Anan'Eva, A. N. Bugrov, A. T. Dideikin, and E. M. Ivankova, "Correlation between structure and resistance of composites based on polystyrene and multilayered graphene oxide," Наносистемыл: физика, химия, математика, vol. 8, nо. 2 2017, pp. 266-271.

25. Kenanakis, G., K. C. Vasilopoulos, Z. Viskadourakis, N-M. Barkoula, S. H. Anastasiadis, M. Kafesaki, E. N. Economou, and C. M. Soukoulis, "Electromagnetic shielding effectiveness and mechanical properties of graphite-based polymeric films,"Applied Physics A. vol. 122 , no. 9, 2016, pp. 802.

26. Gelir, Ali, Onder Yargi, Berkay Sarli, Utkan Sahinturk, and Baki Aksakal. "Monitoring the film formation process of polystyrene/poly acrylamide (PS/PAAm) composite films annealed by IR heating." Polymer Engineering \& Science(2017).

27. Yang, Jintao, Minjie Wu, Feng Chen, Zhengdong Fei, and Mingqiang Zhong. "Preparation, characterization, and supercritical carbon dioxide foaming of polystyrene/graphene oxide composites." The Journal of Supercritical Fluids 56, no. 2, 2011, pp. 201-207.

28. Huo, J. M.; Ko, T. H.; Yang, W.-T.; Lin, J. C.; Jiang, G. J.; Xie, W.; Pan, W. P. J Appl Polym Sci, vol. 91, 2004, pp. 101.

29. Wang, H.-W.; Chang, K.-C.; Yeh, J.-M.; Liou, S.-J. J Appl Polym Sci vol. 91,2004, pp. 1368.

30. Kjoller, Kevin, and Craig B. Prater. "Nanoscale Infrared Spectroscopy of Polymer Composites." American Laboratory (2014).

31. Mak, Kin Fai, Long Ju, Feng Wang, and Tony F. Heinz. "Optical spectroscopy of graphene: from the far infrared to the ultraviolet," Solid State Communications. vol.152, no. 15, 2012, pp. 1341-1349.

32. Martínez, Mariana Castro, Susana Hernández López, and Enrique Vigueras Santiago, "Relationship between polymer dielectric constant and percolation threshold in conductive poly (styrene)-type polymer and carbon black composites," Journal of Nanomaterials, vol. 2015, 2015, pp. 7.

33. Song, L. N.; Xiao, M.; Meng, Y. Z. Compos Sci Technol. vol. 66 , 2006, pp. 2156

34. Mendoza, Moises Oviedo, Edna M. Valenzuela-Acosta, Evgen Prokhorov, Gabriel Luna-Barcenas, and Siva Kumar-Krishnan." Percolation phenomena in polymer nanocomposites." Threshold 3: 4

35. Campos, F.M.; Couto, J.A.; Hogg, T.A, "Influence of phenolic acids on growth and inactivation of Oenococcus oeni and Lactobacillus hilgardii," J. Appl. Microbiol. vol. 94, 2003, pp. 167-174.

36. Nohynek, L.J.; Alakomi, H.; Kähkönen, M.P.; Heinonen, M.; Ilkka, M.; Puupponen-pimiä, R.H.; Helander, I.M. Berry phenolics: "Antimicrobial properties and mechanisms of action against severe human pathogens" Nutr. Cancer, vol. 54, 2006, pp. 18-32.

\section{AUTHORS PROFILE}

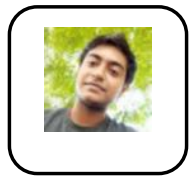

Soumya Chatterjee, has completed B.Tech in Department of Chemical Engineering in Haldia Institute of Technology, Haldia, West Bengal, India. He is working in materials for photo-catalysis applications.

Devargya Chakraborty, has completed B.Tech in Department of Chemical Engineering in Haldia Institute of Technology, Haldia, West Bengal, India

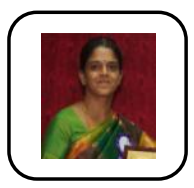

T.Theivasanthi, Assistant Professor in Physics of Kalasalingam University doing research in nanomaterials nanotechnology; has 15 years of teaching experience; published many research articles/ books. She is a life member of Indian Science Congress Association and Magnetics Society of India; member of International Association of Advanced Materials; serving as Editorial Board Member/ reviewer for some scientific journals; lead editor in JNNN special issue (SAGE Publications, UK); achieved many awards/ honours/ recognitions. She has achieved World Record in LIMCA Book of Records-2015 for nanotechnology invention "World's first superparamagnetic plants materials" - named "Santhi Particles.

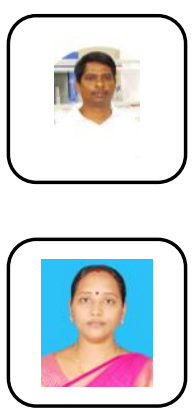

N.Hariram, Currently working as Assistant Professor in Department of Biotechnology, Kalasalingam Academy of Research and Education. His area of interest includes Industrial Enzymes, Nanoparticle human growth factor, Arbuscular mycorrhizae. He has published more than 20 research articles in leading international journals Education and her field of interests are thin films and green synthesis of nanomaterials. She has published 6 papers in national and international journals.

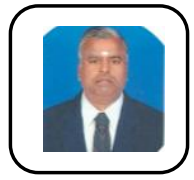

P.G.Gurusamy Pandian, Currently working as Professor in Department of Automobile Engineering, Kalasalingam Academy of Research and Education. He has published more than 16 research articles in leading international journals 